\title{
Survey of Ankle Brachial Pressure Index Use and its Perceived Barriers by General Practitioners in the UK
}

$\begin{array}{ll}\text { Corresponding author: } & \text { Mr. Ramesh Yap Kannan } \\ & \text { Clinical Research Fellow } \\ & \text { Department of Cardiovascular Sciences } \\ & \text { Robert Kilpatrick Clinical Sciences Building } \\ & \text { University of Leicester } \\ \text { Infirmary Road, Leicester, LE2 7LX }\end{array}$

Yap Kannan $\mathrm{R}^{1,2}$, Dattani $\mathrm{N}^{1}$, Sayers $\mathrm{RD}^{1}$, Bown $\mathrm{MJ}^{1,2}$

${ }^{1}$ Department of Cardiovascular Sciences, University of Leicester

${ }^{2}$ NIHR Leicester Cardiovascular Biomedical Research Unit

Key words: Ankle brachial pressure index (ABPI), peripheral arterial disease (PAD), general practitioners (GPs)

\section{Research question:}

- Is there a better way to increase survey response rates from General practitioners?

- Is ABPI feasible as a diagnostic test in primary care?

- If not feasible, what are the perceived limitations of its use in primary care?

\section{ABSTRACT}

Background: Peripheral arterial disease (PAD) is often undetected until complications arise, despite it being a major healthcare burden and an independent risk factor for cardiovascular death and systemic atherosclerosis. Appropriate diagnostic tools are as important as clinical knowledge and skill to investigate patients for PAD. Currently the ankle brachial pressure index $(A B P I)$ is the recommended diagnostic tool for PAD.

Purpose: We explore current opinions on ABPI by general practitioners (GPs) and the limitations to its implementation in primary care practice.

Methods: GPs attending a regional one day study event, were surveyed in October 2014. Survey questionnaires were placed at the top of each conference pack 
for each attendee. Participants were requested to complete the questionnaire at the beginning of the day, at three breaks and at the conclusion of the study day. The survey questionnaire was modelled from the $A B I$ utilisation survey questionnaire used in the PARTNERS preceptorship study.

Results: All respondents were GPs, with a survey response rate of $77.1 \%$. All respondents regarded $A B P I$ as an important test, that is primarily performed by nursing staff $(79.5 \%)$ in their respective GP surgeries. $70 \%$ and $97 \%$ of GPs found ABPI useful for the diagnosis of asymptomatic and symptomatic PAD respectively. Nevertheless only $69 \%$ of GPs regarded ABPI as a feasible test in primary care practice. Time constraints (84\%), staff availability $(89 \%)$ and staff training $(72 \%)$ were cited as the main limitations to its use.

Conclusions: Targeted training of nursing staff may improve ABPI utilisation, although a less time consuming test for PAD, may be another option. 


\section{INTRODUCTION}

Peripheral arterial disease (PAD) is an early indicator of systemic atherosclerosis ${ }^{1}$ and an independent predictor of cardiovascular mortality ${ }^{2,3}$. It is a major health and financial burden ${ }^{4}$. PAD affects about $20-22 \%$ of people over the age of $45^{5}$. Of these patients, about $10 \%$ have typical intermittent claudication ${ }^{6}$. The severity of PAD symptoms generally depends on the severity of both large vessel stenosis/occlusions and the presence or absence of microvascular disease ${ }^{7}$. Therefore, patients with complete arterial occlusion may remain asymptomatic ${ }^{8}$. Patients with asymptomatic PAD have a 3 to 4 fold excess risk of having coronary artery disease and cerebrovascular disease ${ }^{5,9}$. Recent focus has been on the primary prevention of this disease ${ }^{10}$, by improving the diagnostic practices in primary care $^{11}$. Currently the ankle brachial pressure index (ABPI) is the recommended diagnostic tool for $P A D^{12,13}$.

Recent surveys on the use of ABPI have suggested that primary care practitioners should receive targeted training to perform and analyse ABPIs ${ }^{14}$. Similar recommendations were made over a decade ago, following a large multicentre programme that assessed the practice and perceptions of primary care clinicians, with the PAD Awareness, Risk and Treatment: New Resources for Survival (PARTNERS) in the US ${ }^{11}$. Following this, a PARTNERS preceptorship program enrolled and trained primary care staff in the technique of performing and interpreting ABPIs. An ABPI utilization survey conducted on participants of both the PARTNERS and the PARTNERS preceptorship program, summarized that primary care clinicians accepted ABPI as a simple diagnostic tool and their role to diagnose PAD despite existing barriers ${ }^{15}$. Nevertheless, evidence to support the uptake of ABPIs in primary care is lacking in the US and worldwide.

The purpose of this survey was to assess if English general practitioners (GPs) regarded $\mathrm{ABPI}$ to be an important test and what were the potential limitations to its implementation in a primary care setting in the UK. 


\section{METHODS}

The Leicestershire, Northamptonshire and Rutland regional ethics committee 1 was consulted prior to conducting the survey. Ethical approval was deemed unnecessary. A survey was conducted on GPs attending a one day 'GP masterclass regional study day' at the University of Leicester conference centre in October 2014. The whole day event was organised by Spire Healthcare Leicester and was open to all GPs in the UK. On the day of the event, participants were seated in clusters. For each seat, survey questionnaires were placed at the top of the conference packs. Following the opening address by the chairperson, the researcher (RYK) and his research was briefly introduced. The chairperson requested all attendees to complete the survey questionnaire and the event feedback form prior to the first lecture. The request was repeated at three break sessions and at the end of the event. Participants were requested to leave survey responses on their table at the end of the day. Participants were informed of the availability of the researcher throughout the day, if there were any queries.

The GP masterclass regional study day organised by the Spire Leicester was initiated in 2012. It is designed to assist GPs in meeting their revalidation needs by collecting continuing professional development credits, in addition to networking opportunities. The event has a good attendance record over the past two years (148 and 168 respectively). The event feedback from was introduced in the events second year (2013). The event feedback questionnaire response rate in 2013 was $61.9 \%$ (104 of 168 attendees). The survey was conducted in this manner owing to a better response rate with a direct face to face approach 16,17 .

A cross sectional survey was conducted, using a survey questionnaire modelled from the $A B I$ utilization survey originally created by the steering committee of the PARTNERS preceptorship program in the US ${ }^{15}$, with minor relevant modifications to suit the UK healthcare system and to allow comparisons to be made. Like the utility questionnaire, this was a multiple choice close-ended questionnaire. The survey questionnaire comprised of eight questions (Figure 1). The first and second question identified the participants' profession and opinions on diagnostic options for PAD. The remaining questions focussed on ABPI. These included who performs the test, how often it is used, how useful has it been in the participant's practice, how feasible it is to incorporate it into practice, whether it is a good screening tool for select patient groups and finally what are the perceived limitations to its use in primary care practice. The survey questionnaire was piloted on members of staff within the department and the departmental statistician with an interest in survey questionnaires. Modifications were made based on suggestions and feedback obtained. 
Raw data was double entered into the SPSS data entry software. All variables were transcribed with the help of a codebook. All data collected on the questionnaires were anonymous. Missing values were coded in the SPSS programme and included in the data analysis.

\section{RESULTS}

A total of 118 GPs attended the study day. The survey questionnaire response rate was $77.1 \%$ (91 of 118 attendees) compared to the event feedback response rate which was $84.7 \%$ (100 of 118 attendees). All 91 respondents were GPs. The results attempt to answer five questions. These were whether ABPI is regarded as an important test (question 2), whether ABPI was utilised and if so, who is involved (questions 3 and 4), to gauge perceived importance of $\mathrm{ABPI}$ for PAD diagnosis (question 5 and 6), whether $\mathrm{ABPI}$ as a diagnostic test for PAD is feasible in primary care (question 7) and if so, what are the limitations to its use (question 8). Results are summarised in Figure 2.

\section{Importance of diagnostic tests for PAD diagnosis}

All respondents felt that risk assessment and $A B P I$ played an important role in PAD diagnosis. Opinions on the role of questionnaires and ankle pressures were divided. Similarly most GPs were unsure of the role of TBPI and toe pressures.

\section{ABPI utilization and staff involvement in PAD diagnosis}

The vast majority of ABPIs were performed by nurses (26.1\% nurse practitioners, $36.4 \%$ registered nurses and $17 \%$ district nurses) according to the respondents with the majority of GP surgeries utilizing ABPI on a monthly (42\%) to annual (30\%) basis.

\section{Perceived utility of ABPI for the care of PAD}

The majority of GPs found ABPI to be more useful for the diagnosis and clinical management of symptomatic patients compared to asymptomatic patients. As a screening tool for, the respondents felt that ABPI was most useful in diabetes, followed by the elderly and patients with chronic renal failure, but was least useful for healthy patients.

\section{Feasibility of ABPI in GP practice}

Although the vast majority of respondents deemed ABPI to be either moderately (54\%) or very feasible (15\%), a third (31\%) deemed it to be not feasible. 


\section{Limitations to ABPI implementation}

The limitations were divided into 7 broad categories. These included administrative (time and financial constraints), structural (availability of space), ABPI related (clinical significance of $\mathrm{ABPI}$ and $\mathrm{ABPI}$ interpretation), patient-related (willingness), staff-related (availability, willingness and training), equipment-related (availability of doppler and cuffs) and test performance-related issues (application of cuff, performance of walk test or handheld doppler examination or the presence of wounds).

\section{Limitations to implementation - administrative}

$84 \%$ respondents regarded time constraints to be a major or moderate limitation, with the opinion on financial constraints divided in this survey.

\section{Limitations to implementation - structural}

Just over half of the respondents viewed the availability of space within the GP surgery as a major or moderate limitation.

\section{Limitations to implementation - ABPI as a test}

Under half $(43 \%)$ of the 74 respondents felt that the clinical significance of ABPI was not a limitation to its use. Interestingly, the majority of respondents, found interpreting ABPI results as a major or moderate $(51 \%)$.

\section{Limitations to implementation - patient related}

Patient willingness to have $\mathrm{ABPI}$ as a test was not a limitation in most respondents (83\%).

\section{Limitations to implementation - staff related}

The vast majority (89\%) of the respondents felt staff availability was a major or moderate limitation to ABPI use. Similarly $72 \%$ respondents regarded staff training to be a major or moderate limitation. Opinion on staff willingness being a limitation to ABPI performance was inconclusive.

\section{Limitations to implementation - equipment related}

$62 \%$ regarded the availability of doppler and cuff availability to be a major or moderate limitation respectively.

\section{Limitations to implementation - test performance related}

A third of respondents did not view the application of cuff to be a limitation. However, $66 \%$ viewed performance of the walk test and $68 \%$ viewed the presence of wounds to be main 
limitations. Although only $3.4 \%$ GPs admitted to performing ABPIs, it was interesting to note that $61 \%$ of the respondents regarded performing the doppler examination to be a major or moderate limitation.

\section{DISCUSSION}

Commissioners and providers are primarily responsible for implementing the National Institute for Health and Care Excellence (NICE) pathway for lower limb peripheral arterial disease in the UK ${ }^{18}$. As these are primarily GPs, our survey focused at GPs to provide a better insight into practical aspects that aid or hinder the implementation and facilitation of ABPI use in primary care practice. All participants in our survey were GPs (100\%), compared to the cohort studied in the PARTNERS program (54\% physicians), PARTNERS Preceptorship (73\% physicians) and in the most recent survey by Davies et al (55\% GPs). Our survey findings reflect those of the ATTEST study findings in which French GPs performed $A B P I$ in only a third of the patients with $P A D^{19}$. ABPI was mainly performed by nurses $(79.5 \%)$ in this survey, compared to the PARTNERS program (38\%) and the survey conducted by Davies et al (67.4\%). Respondents of this survey agree with previous survey findings, that $\mathrm{ABPI}$ is more useful in symptomatic than asymptomatic $\mathrm{PAD}^{15}$. As a screening tool for PAD in diabetics, ABPI is generally accepted (78\%) by survey respondents. This response is in line with current NICE guidelines ${ }^{18}$. It is interesting to note that more than half the respondents (55\%) felt ABPI to be a useful screening tool for PAD in patients with chronic renal failure or who were elderly, which reflects an understanding by GPs of factors that pose a risk to PAD. Although, the US preventative services task force (USPSTF) does not recommend $A B P I$ as a screening test ${ }^{20}$, the NICE guidelines recommends assessment of PAD in those with suspected PAD, whether symptomatic or not ${ }^{18}$.

Unlike previous surveys ${ }^{15}$, where the majority of clinicians in the PARTNERS program (90\%) and Preceptorship program ( $88 \%$ ) believed ABPI to be a feasible test, in our survey only two thirds (69\%) regarded it as being feasible. Using a $70 \%$ or more arbritary cut off as significant limitation, the primary limitations are time constraints (84\%), staff availability $(89 \%)$ and staff training (72\%). Time constraints have also been a limitation in previous surveys by Mohler et al $(54 \%)^{15}$ and Davies et al $(72 \%)^{14}$. It is intriguing that all surveys conducted to date including this one, have highlighted time constraints and staff training to be primary limitations to ABPI implementation. However, if we used a $50 \%$ cut-off for major or moderate limitations, as used by previous surveys ${ }^{14,15}$, financial constraints $(61 \%)$, space 
availability (57\%), cuff and doppler availability (62\% each), presence of wounds (68\%), performance of walk test (66\%) and the interpretation of $\mathrm{ABPI}(51 \%)$ are limiting factors.

The NICE guideline development group consider the incremental resource needs for ABPI measurements to be small compared to the benefits of early PAD diagnosis ${ }^{4}$ and this test adds between 5 to 15 minutes to the time needed for clinical examination ${ }^{18}$. However attempts to reduce the time for ABPI measurements, such as using the pulse oximeter instead of the handheld doppler ${ }^{21,22}$ or an oscillometric automated blood pressure device ${ }^{23}$, the reliability of such alternatives have not been widely accepted. Under such circumstances, delegation of ABPI performance to competent and trained staff would appear reasonable. Targeted formal training of students have been shown to enhance the reliability of $\mathrm{ABPI}^{24}$. Although, the targeted educational initiative was studied in the $\mathrm{ABI}$ utilization survey ${ }^{15}$, the follow up after the training survey was conducted a few months after the training program. Clinical audit tools for PAD in primary care and an online education tool are available for healthcare professionals in the $\mathrm{UK}^{18}$. An ideal test should be reliable, quick to perform, easy to use, interpret and be affordable. Such a test would circumvent many of these limitations. Alternatively further studies to assess the true impact of targeted ABPI training and the sustainability of practice, should be conducted after an adequate period of time.

\section{STRENGTHS AND LIMITATIONS}

The advantage of this study is the encouraging response rate from GPs. This survey does not address the actual performance of ABPIs, as reflected by the study being less representative of members of staff who actually perform the test, and more representative of clinicians who would request for the test. As the majority of respondents who attended the event were from Leicestershire, it is possible, but unlikely, that these results are not representative of the opinions of GPs nationally. Furthermore, unlike the recent survey by Davies et $\mathrm{al}^{14}$, this survey concentrates less on the actual methods for performing the test, but rather attempts to understand reasons behind why ABPI may or may not be used in primary care.

\section{CONCLUSION}

GPs play more of an administrative role when it comes to performing ABPIs in the UK. Time constraints, staff availability and staff training are the main limitations to its use in primary care. Possible solutions include targeted standardized ABPI training of competent and delegated members of staff. Another alternative is to conduct further research into alternative technologies which may simplify the recognition of peripheral arterial disease. 


\section{CONFLICTS OF INTEREST}

None

\section{FUNDING SOURCES}

None

\section{ACKNOWLEDGEMENT}

We would like to thank Spire Leicester.

\section{REFERENCES}

1. Manfredini F, Malagoni AM, Manfredini R. Ankle brachial pressure index: Faulty or overused? Angiology. 2013;64(2):89-92.

2. Jager A, Kostense PJ, Ruhé HG, et al. Microalbuminuria and peripheral arterial disease are independent predictors of cardiovascular and all-cause mortality, especially among hypertensive subjects : Five-year follow-up of the hoorn study. Arterioscler Thromb Vasc Biol. 1999;19:617-624.

3. Criqui MH, Langer RD, Fronek A, et al. Mortality over a period of 10 years in patients with peripheral arterial disease. N.Engl.J.Med. 1992;326:381-386.

4. NICE clinical guideline 147. Lower limb peripheral arterial disease: Costing report. . 2012.

5. Stoffers HEJH, Rinkens PELM, Kester ADM, Kaiser V, Knottnerus JA. <br />The prevalence of asymptomatic and unrecognized peripheral arterial occlusive disease. International Journal of Epidemiology. 1996;25(2).

6. Schirmang TC, Ahn SH, Murphy TP. Peripheral arterial disease: Update of overview and treatment. Med Health R I. 2009;92:398-402. 
7. Hills AJ, Shalhoub J, Shepherd AC. Peripheral arterial disease. Br J Hosp Med. 2009;70:560-565.

8. Premalatha G, Ravikumar R, Sanjay R, Deepa R, Mohan V. Comparison of colour duplex ultrasound and ankle brachial pressure index measurements in peripheral vascular disease in type 2 diabetic patients with foot infections. J Assoc Physicians India. 2002;50:1240-1244.

9. Golomb BA, Dang TT, Criqui MH. Peripheral arterial disease morbidity and mortality implications. Circulation. 2006;114:688-699.

10. Mukherjee D, Eagle K. The importance of early diagnosis and treatment in peripheral arterial disease: Insights from the PARTNERS and REACH registries. Curr Vasc Pharmacol. 2010;8:293-300.

11. Hirsch AT, Criqui MH, Treat-Jacobson D, et al. Peripheral arterial disease detection, awareness and treatment in primary care. JAMA. 2001;286:1317-1324.

12. NICE. Lower limb peripheral arterial disease:Primary care (clinical audit tool: Implementing NICE guidance). . 2012;CG 147.

13. Norgren L, Hiatt WR, Dormandy JA, Nehler MR, Harris KA, Fowkes FGR. Inter-society consensus for the management of peripheral arterial disease (TASC II). Journal of Vascular Surgery. 2007;45(1):S5a - S63a.

14. Davies JH, Kenkre J, Williams EM. Current utility of the ankle-brachial index (ABI) in general practice: Implications for its use in cardiovascular disease screening. BMC Family Practice. 2014;15(69):1-11.

15. Mohler ER, Treat-Jacobson D, Reilly MP, et al. Utility and barriers to performance of the ankle-brachial index in primary care practice. Vascular Medicine. 2004;9:253-260. 
16. Bowling A. Mode of questionnaire administration can have effects on data quality. Journal of Public Health. 2005;27(3):281-291.

17. Daniel AJ, Chavan PV, Rajashri SP, Kumar A, Vijayanath V. Telephone survey versus face to face survey as a method of data collection. Journal of Medical Research and Practice. 2013;2(7):191-196.

18. NICE. Lower limb peripheral arterial disease overview. National Institute for Health and Care Excellence. 2015.

19. Blacher J, Cacoub P, Luizy F, et al. Peripheral arterial disease versus other localizations of vascular disease: The ATTEST study. J Vasc Surg. 2006;44:314-318.

20. Moyer VA. Screening for peripheral artery disease and cardiovascular disease risk assessment with the ankle brachial index in adults: U.S. preventive services task force recommendation statement. Ann Intern Med. 2013;159:342-348.

21. Papanas N, Kakagia D, Papatheodorou K, et al. Lanarkshire oximetry index as a diagnostic tool for peripheral arterial disease in type 2 diabetes: A pilot study. Angiology. 2010;61(4):388-391.

22. Bianchi J, Zamiri M, Loney M, McIntosh H, Dawe RS, Douglas WS. Pulse oximetry index: A simple arterial assessment for patients with venous disease . J Wound Care. 2008;17(7):327.

23. Ena J, Lozano T, Verdú G, Argente CR, González VL. Accuracy of Ankle-Brachial index obtained by automated blood pressure measuring devices in patients with diabetes mellitus. Diabetes Research and Clinical Practice. 2011;92(3):329-336. 
24. Ray SA, Buckenham TM, Belli AM, Taylor RS, Dormandy JA. The predictive value of laser doppler fluximetry and transcutaneous oximetry for clinical outcome in patients undergoing revascularization for severe leg ischaemia. Eur J Vasc Endovasc Surg. $1997 ; 13: 54-59$. 
Figure 1: Peripheral Arterial Disease Survey Questionnaire

Peripheral Arterial Disease Screening Survey

We, at the Vascular Surgery Research Group, University of Leicester kindly request for a few minutes of your time to complete this survey to assess current practice in the diagnosis of Peripheral Arterial Disease (PAD) at primary care facilities.

1. Please select your profession

$\begin{array}{llll}\Gamma & \text { General Practitioners } & \Gamma & \text { Health Care Assistant } \\ \Gamma & \text { Registered Nurse } & \Gamma & \text { Technician } \\ \Gamma \quad & \text { Nurse Practitioner } & & \text { Other }\end{array}$

2. Which of the following do you consider important in diagnosing PAD?

\begin{tabular}{|c|c|c|}
\hline \multirow[b]{2}{*}{ Risk Factors } & Yes & No \\
\hline & $\Gamma$ & $\Gamma$ \\
\hline Pulse Examination & $\Gamma$ & $\Gamma$ \\
\hline Questionnaires & $\Gamma$ & $\Gamma$ \\
\hline $\begin{array}{l}\text { Ankle Brachial Pressure } \\
\text { Index (ABPI) }\end{array}$ & $\Gamma$ & $\Gamma$ \\
\hline Ankle Pressures & $\Gamma$ & $\Gamma$ \\
\hline $\begin{array}{l}\text { Toe Brachial Pressure Index } \\
\text { (TBPI) }\end{array}$ & $\Gamma$ & $\Gamma$ \\
\hline Toe Pressures & $\Gamma$ & Г \\
\hline \multicolumn{3}{|c|}{ 3. Who performs the ABPI at your practice? } \\
\hline General Practitioner & $\Gamma$ & Health Care Assistant \\
\hline Г Nurse Practitioner & $\Gamma$ & Technician \\
\hline Г Registered Nurse & $\Gamma$ & Other \\
\hline \multicolumn{3}{|c|}{ 4. How often do you use the ABPI? } \\
\hline Г Weekly & $\Gamma$ & Annually \\
\hline Monthly & | & Never \\
\hline
\end{tabular}

5. How useful have you found the ABPI to be in the diagnosis and clinical management of

$\begin{array}{lccc} & \text { Very Useful } & \begin{array}{c}\text { Moderately } \\ \text { Useful }\end{array} & \text { Not Useful } \\ \begin{array}{l}\text { Asymptomatic } \\ \text { PAD }\end{array} & \Gamma & \Gamma & Г \\ \begin{array}{l}\text { Symptomatic } \\ \text { PAD }\end{array} & \Gamma & \Gamma & \Gamma\end{array}$

6. How feasible is incorporating the ABPI into your daily practice?

$\Gamma$ Very Feasible $\Gamma$ Moderately Feasible
7. Is $A B P I$ a good screening tool for PAD in the following patients?

\begin{tabular}{|c|c|c|c|}
\hline & Yes & No & Unsure \\
\hline $\begin{array}{l}\text { Healthy } \\
\text { patients }\end{array}$ & $\Gamma$ & $\Gamma$ & $\Gamma$ \\
\hline Diabetics & $\Gamma$ & $\Gamma$ & Г \\
\hline $\begin{array}{l}\text { Chronic } \\
\text { Renal } \\
\text { Failure }\end{array}$ & $\Gamma$ & $\Gamma$ & $\Gamma$ \\
\hline $\begin{array}{l}\text { Elderly (>65 } \\
\text { years) }\end{array}$ & $\Gamma$ & $\Gamma$ & Г \\
\hline
\end{tabular}

8. What factors if any, limit the utilization of the ABPI in your clinical practice?

$$
\begin{array}{llll}
\text { No } & \text { Major } & \text { Moderate } & \text { Minor } \\
\text { limitation } & \text { limitation } & \text { limitation } & \text { limitation }
\end{array}
$$

Time Constraints

Financial Constraints $\Gamma \quad \Gamma \quad \Gamma$

Clinical Significance $Г \quad \Gamma \quad \Gamma$

Staff Availability $Г \quad \Gamma \quad \Gamma$

Patient Willingness $\Gamma \quad \Gamma \quad \Gamma$

Staff Willingness $\Gamma \quad \Gamma \quad \Gamma$

$\begin{array}{llll}\text { Staff Training } & \Gamma & \Gamma\end{array}$

Availability of Space $\Gamma \quad \Gamma \quad \Gamma$

Availability of Doppler $Г \quad \Gamma \quad \Gamma$

Availability of Cuffs $Г \quad \Gamma \quad \Gamma$

Application of Cuff $\quad$ Г

Performing Walk test $Г \quad \Gamma \quad \Gamma$

Presence of Wounds $\Gamma \quad \Gamma \quad \Gamma$

Performing Handheld $Г \quad \Gamma \quad \Gamma$

Doppler examination

ABPI interpretation $\Gamma \quad \Gamma \quad \Gamma$ 
Figure 2: Peripheral Arterial Disease Survey Responses

Q2: Which of the following do you consider important in diagnosing PAD?

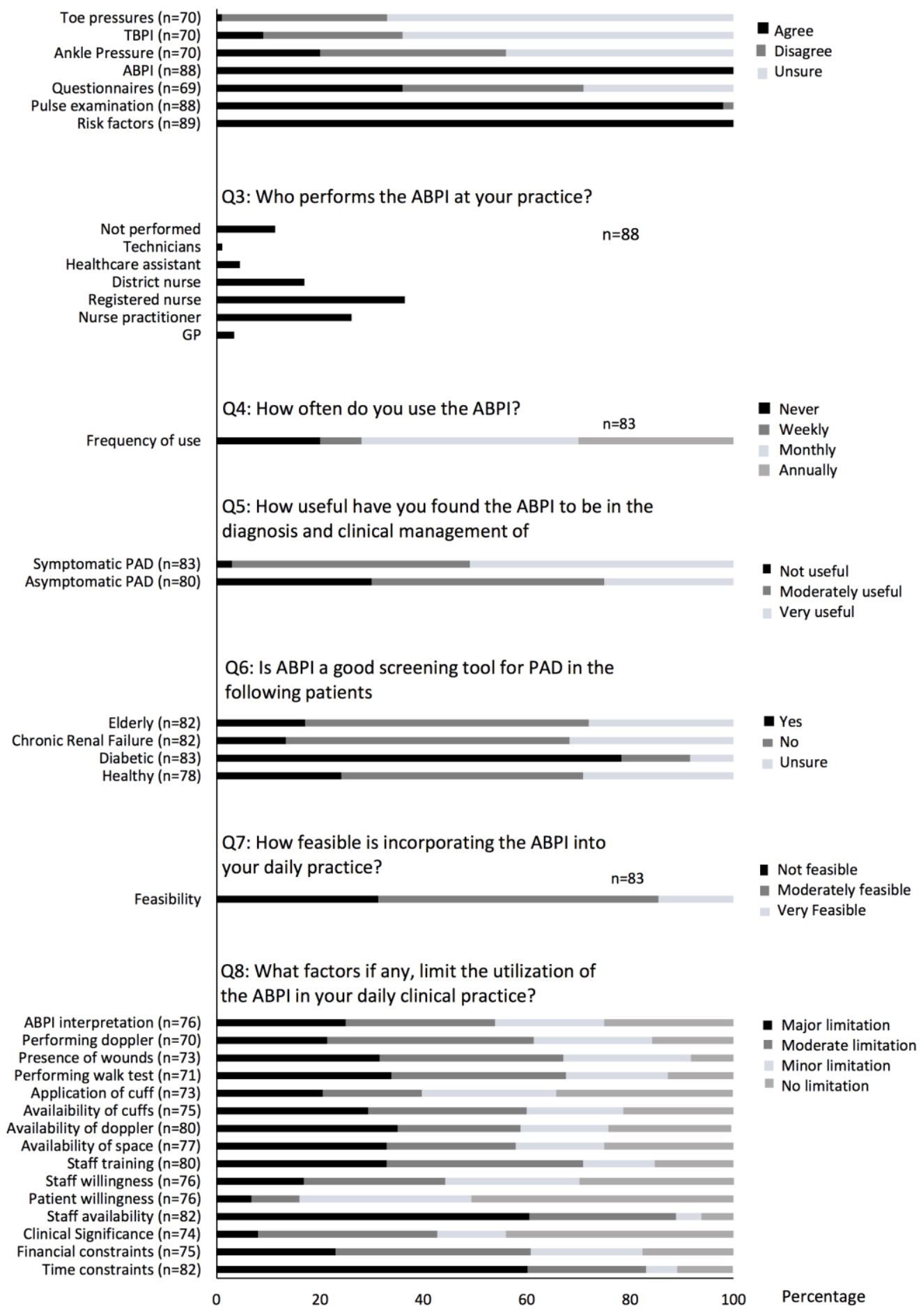

